\title{
Anode Reaction in Pressurized Solid Oxide Fuel Cells*
}

\author{
Akira HASHIMOTO**, Kenichiro KOSAKA***, Norihisa MATAKE***, \\ Akihiro YAMASHITA***, Yoshinori KOBAYASHI****, \\ Tatsuo KABATA***** and Kazuo TOMIDA***** \\ **Institute of Industrial Science, The University of Tokyo, \\ 4-6-1, Komaba, Meguro-ku, Tokyo, Japan \\ ${ }^{\star * *}$ Mitsubishi Heavy Industries, Nagasaki Research \& Development Center, \\ 5-717-1, Fukahori-machi, Nagasaki, Japan \\ **** Power Systems Headquarter, Mitsubishi Heavy Industries, Ltd., \\ 3-1 Minatomirai 3-chome, Nishi-ku, Yokohama, Kanagawa 220-8401, Japan \\ ***** Mitsubishi Heavy Industries, Nagasaki Shipyard \& Machinery Works, \\ 1-1, Akunoura-machi, Nagasaki, Japan
}

\begin{abstract}
Pressurized solid oxide fuel cells (SOFCs) using a gas turbine for the bottoming cycle convert energy very efficiently. The performance of a tubular SOFC made by a plasma spray coating method was measured at levels of pressure between 0.1 and $0.59 \mathrm{MPa}$. The cell voltage increased with the operating pressure. Moreover, it was determined that polarization decreased under pressurization, using the current interruption. Anode performance was also measured with a reference electrode. The estimated concentration overvoltage from the measurement of permeability was used to estimate the activation overvoltage of the anode. The anode activation overvoltage was affected by the partial pressure of $\mathrm{H}_{2} \mathrm{O}$ instead than that of $\mathrm{H}_{2}$.
\end{abstract}

Key words: SOFCs, Pressurized Operation, Current Interruption, Consumption Overvoltage, Activation Overvoltage

\section{Introduction}

Highly efficient power generation systems are required to solve global warming and energy issues. Fuel cells, which convert the chemical energy of fuel directly to electrical energy, can be integrated into power generation systems that are expected to be more efficient than those in conventional power plants. Solid oxide fuel cells (SOFCs) have a number of advantages that make them suitable for use in power plants ${ }^{1)}$.

1) SOFCs have a high operating temperature of $900 \sim 1000^{\circ} \mathrm{C}$, such that high-temperature waste heat can be utilized as the topping cycle of a gas turbine, achieving high electrical efficiency of over $60 \%$ of the higher heating value (HHV).

2) SOFCs utilize fuel including both carbon monoxide and hydrogen because oxygen ions move through the electrolyte to the anode and react with the fuel. Various fuels such as natural gas and gasified coal gas can be utilized.

3) SOFCs with a high operating temperature utilize waste heat for the internal reforming of methane fuel and thus improve efficiency.

4) Since all cell components are solid, there is no evaporation or leakage of cell components, and thus provides excellent durability and maintainability.

The principle of the SOFC is shown in Fig. 1. Porous electrodes are placed on either

*Received 18 May, 2010 (№. 10-0210) [DOI: 10.1299/jpes.4.348]

Copyright $\odot 2010$ by JSME 
side of electrolyte, which has high oxygen ion conductivity. When fuel and oxidant are supplied to the cell, oxygen is ionized on the cathode side and passes through the electrolyte, reacting with the fuel and then $\mathrm{H}_{2} \mathrm{O}, \mathrm{CO}_{2}$, and air is discharged as exhaust. The flow of oxygen ions through the electrolyte causes an electrical current, and power is generated.

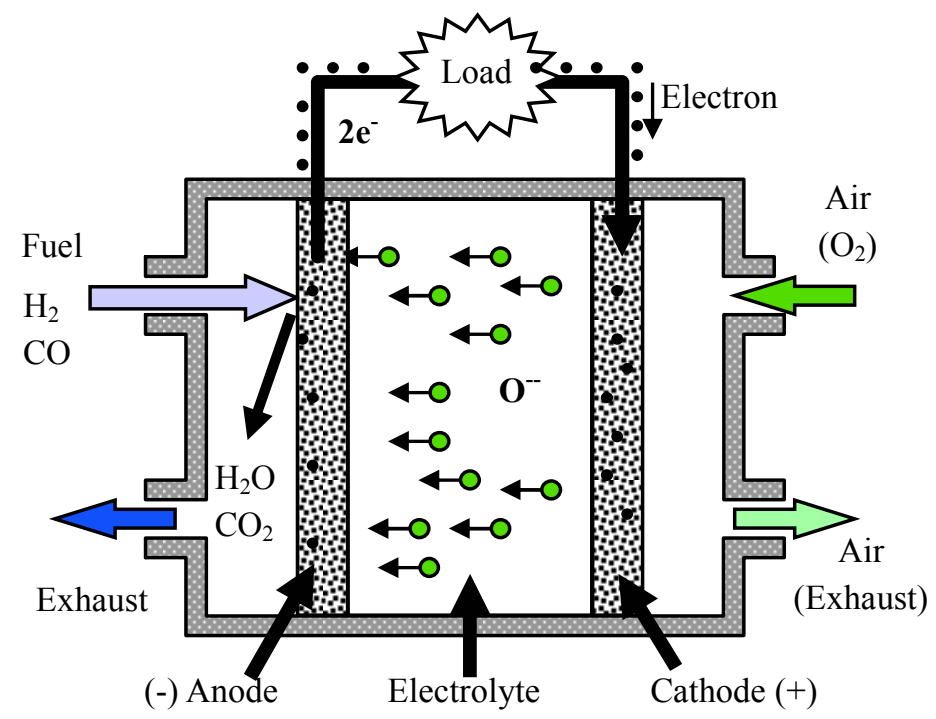

Fig. 1 Principle of solid oxide fuel cell

Although the fuel cell has a high conversion efficiency from chemical to electrical energy, the exhaust gas still contains unreacted fuel. This residual fuel with waste heat can be effectively utilized in the bottoming cycle, and thus further improve the generating efficiency. However, while integration of a gas turbine is especially effective, the cell must be pressurized so to operate at the gas turbine inlet pressure.

In addition to the development of a high-performance cell, making the above system requires a way to predict the performance of a cell and thus optimize the cell tube microstructure, and the management of the temperature distribution of the module. We aimed to make a prediction method that will reflect the various pressure and temperature conditions in conjunction with fuels such as natural gas and gasified coal gas.

Most of the research to date on SOFCs involves testing under atmospheric pressure and there are very few reports on pressurized conditions. Also, research on electrode performance (which has a major influence on cell performance) has also tended to focus on elemental testing of small cells under atmospheric testing. We evaluated the effect of pressurized gas composition on anode overvoltage and conducted pressurized generating tests by using a tubular cell stack made by plasma spray. The performance of the cell when gas concentration and operating pressure were changed when mixed (water, nitrogen, and steam) fuel was used. This is seen as an initial step towards the establishment of a reliable way of predicting cell performance. 


\section{Nomenclature}

$\begin{array}{ll}c_{A} & : \text { Mol concentration of component A } \\ D_{A B} & : \text { Molecular diffusion coefficient of component AB } \\ D_{A B, e} & : \text { Effective diffusion coefficient of component AB } \\ E & : \text { Voltage } \\ F & : \text { Faraday constant } \\ I & : \text { Current } \\ i & : \text { Current density } \\ J_{A} & : \text { Diffusion flux of component A } \\ P_{A} & : \text { Partial pressure of component A } \\ \tau & : \text { Tortuosity } \\ R & : \text { Universal gas constant } \\ T & : \text { Temperature } \\ t & : \text { Substrate tube thickness } \\ \varepsilon & : \text { Porosity } \\ \eta & : \text { Polarization } \\ \eta_{a} & : \text { Activation overvoltage } \\ \eta_{d} & : \text { Concentration overvoltage } \\ \eta_{r} & : \text { Ohmic loss } \\ \eta_{s} & : \text { Slow polarization }\left(\eta_{a}+\eta_{d}\right)\end{array}$

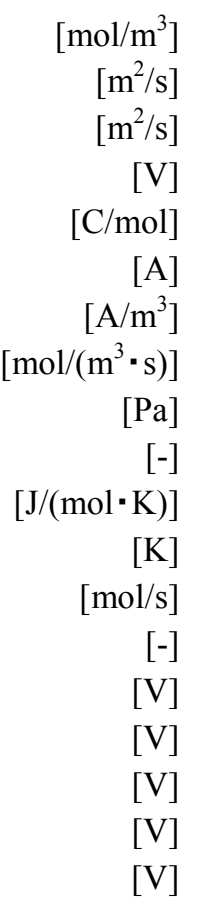

\section{Cell characteristics}

Data on the performance of SOFC in a pressurized condition is needed because SOFC is used in pressurized condition with GT combined system. In this section, we discuss the result of an experiment to test the performance of a tubular type SOFC in a pressurized condition.

\subsection{Test apparatus}

The test apparatus is shown in Fig. 2, and Fig. 3 indicates the arrangement of the fuel feeding tube. To maintain the cell stack temperature at $900^{\circ} \mathrm{C}$, the cell stack was placed in an electric furnace, with the entire furnace set in the pressure vessel. Both fuel and air were quantitatively supplied using mass flowmeters, and the system pressure is kept at the setting value by using a back-pressure control system. The fuel was supplied to the fuel header, passes through the fuel feeding tube to set at the cell stack. The bottom of the cell stack is closed, such that the fuel input at the bottom is returned and used for generating electricity as it rises between the stack and fuel feeding tube. Residual fuel was exhausted via the exhaust header at the top of the cell stack and passed through the drain pot. The cell stack is surrounded by a double-walled tube with air supplied from the bottom inside. The air then rose around the outside of the cell stack, and, after being used for generating electricity, was pushed down the outside of the double-walled tube and discharged from the system.

The tubular cell configuration is shown in Fig. 4, with an observation by an optical microscope of the cell presented in Fig. 5, and the specifications of the tubular cell listed in Table 1. A plasma spray was used to deposit the functional films on the surface of a porous ceramic substrate tube, and thus formed the cell stack. Electricity was generated by supplying fuel to the inside of the substrate tube and air to the outside. A single substrate tube consisted of 22 cells that were connected in series by an interconnect material, and resulted in a 720 -mm long cell stack. ${ }^{2)}$ 


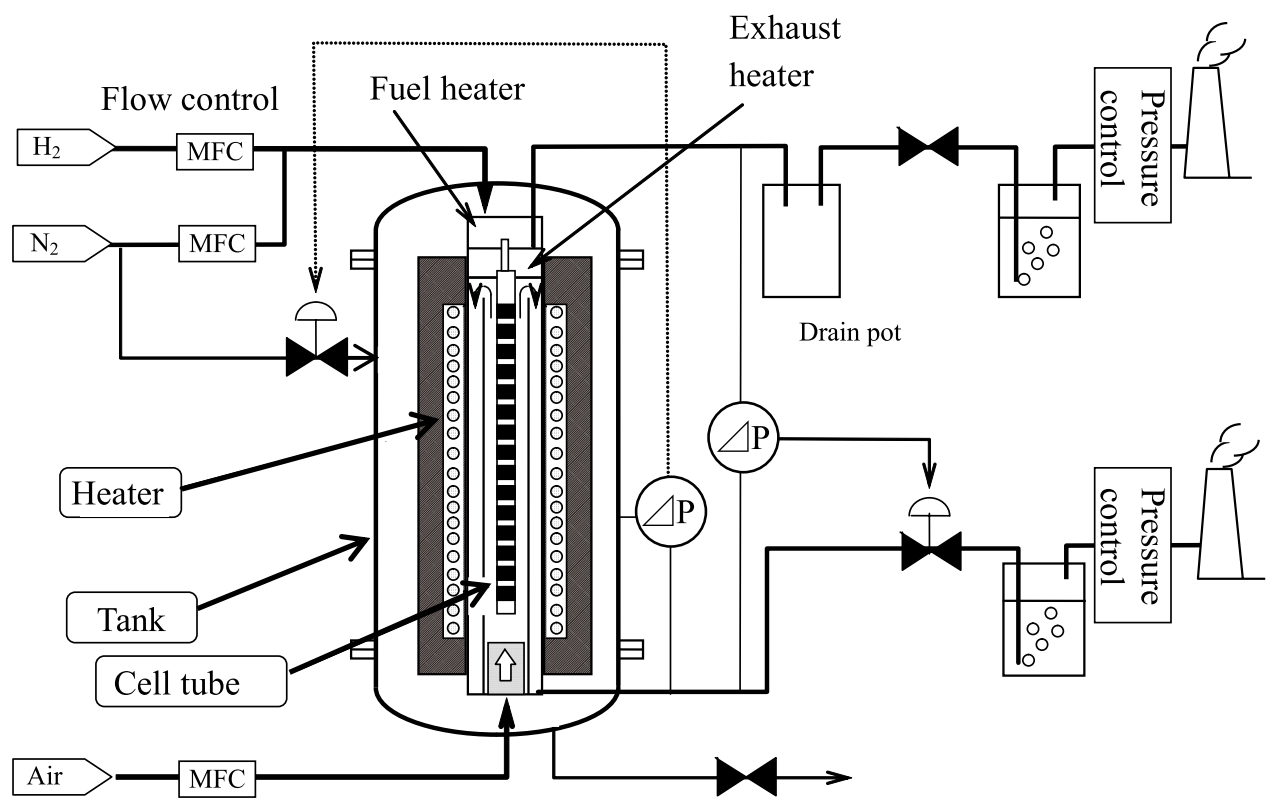

Fig. 2 Schematic view of experimental apparatus

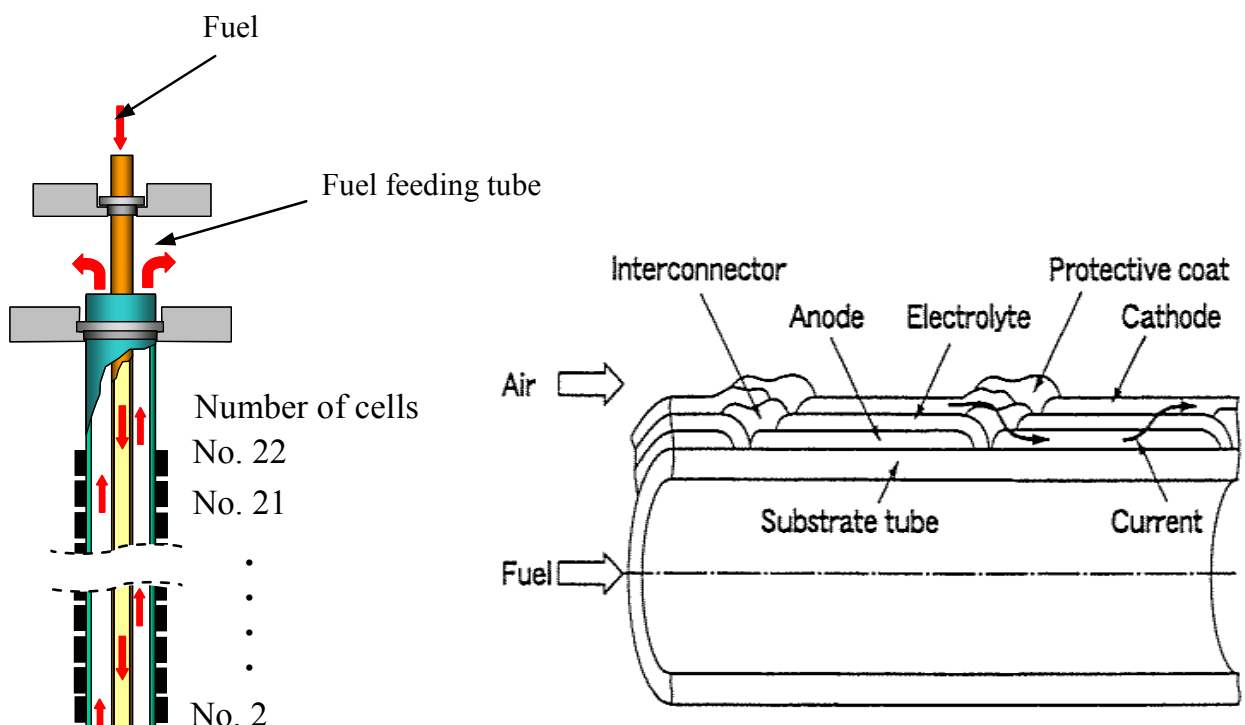

No. 1

Fig. 3 Arrangement of fuel feeding tube

Fig. 4 Tubular cell configuration 


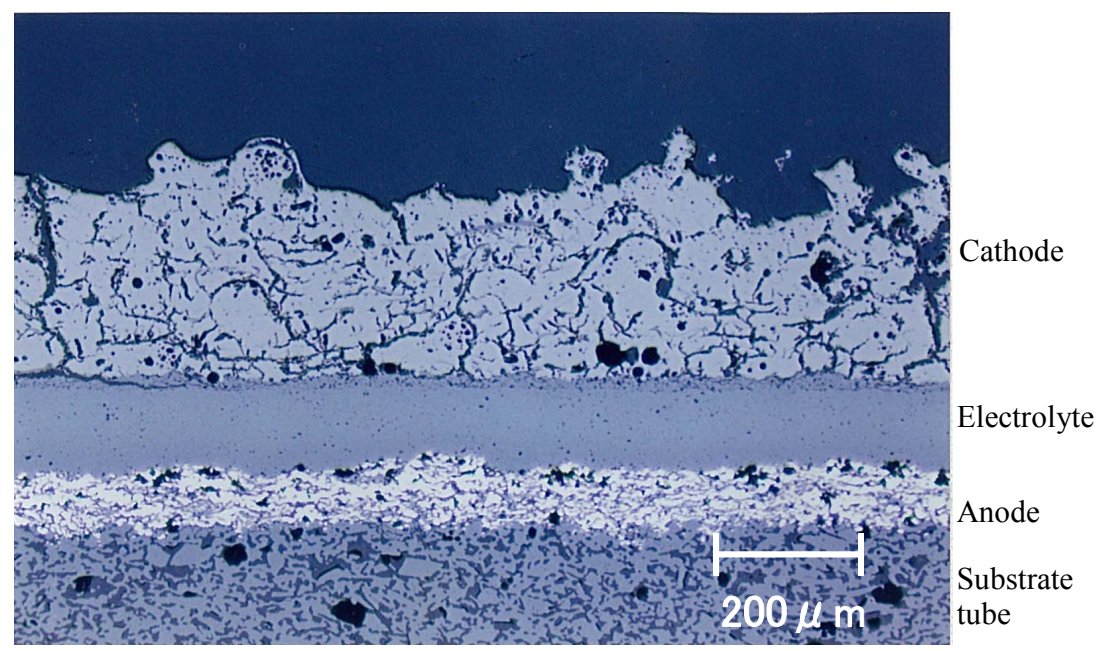

Fig. 5 Optical microscope image of cell

Table 1 Materials and thickness of layer

\begin{tabular}{|l|l|c|}
\hline Layers & Materials & Thickness \\
\hline Anode & $\mathrm{NiO} / \mathrm{YSZ}$ & $80 \sim 110 \mu \mathrm{m}$ \\
\hline Electrolyte & $\mathrm{YSZ}$ & $110 \sim 150 \mu \mathrm{m}$ \\
\hline Cathode & $\mathrm{LaCoO}_{3}$ & $150 \sim 200 \mu \mathrm{m}$ \\
\hline $\begin{array}{l}\text { Interconnect } \\
\text { material }\end{array}$ & $\mathrm{NiAl} / \mathrm{Al}_{2} \mathrm{O}_{3}$ & $200 \sim 250 \mu \mathrm{m}$ \\
\hline Protective coat & $\mathrm{Al}_{2} \mathrm{O}_{3}$ & $200 \mu \mathrm{m}$ \\
\hline Substrate tube & $\mathrm{CSZ}$ & $\Phi 21 \mathrm{~mm} \times 3 \mathrm{~mm}$ thickness \\
\hline
\end{tabular}




\subsection{Test conditions}

The test condition is shown below. The pressure of the compressor outlet is over $1 \mathrm{MPa}$, but experimental conditions are limited by the testing equipment.

Temperature:

$900^{\circ} \mathrm{C}$

Pressure:

Atmospheric $(0.10 \mathrm{MPa} \sim 0.59 \mathrm{MPa}$

Current:

$0 \sim 2.51 \mathrm{~A}$

Oxidant:

Air

Fuel:

Hydrogen/nitrogen/steam mixed gas

\subsection{Test results}

Voltage measurement results for cell No. 21 are shown in Figure 6, with operating pressure at levels between 0.1 to $0.59 \mathrm{MPa}$. Volumetric fuel composition was $\mathrm{H}_{2} / \mathrm{N}_{2} / \mathrm{H}_{2} \mathrm{O}=$ $67 / 30 / 3 \%$ which was one of the inlet conditions of SOFC. The air utilization ratio was $15 \%$ and that of fuel was $60 \%$. The current was $2.51 \mathrm{~A}$. Cell voltage rose with increased pressure and yielded a differential of $0.105 \mathrm{~V}$ between 0.1 and $0.59 \mathrm{MPa}$.

The voltage at $0.10 \mathrm{MPa}$ was taken as standard, and the dotted line in the figure represents the voltage as determined from the rise in electromotive force in accordance with the Nernst equation. The measured rise in voltage of $0.105 \mathrm{~V}$ because of pressurization from 0.1 to $0.59 \mathrm{MPa}$ is greater than the theoretical rise of $0.045 \mathrm{~V}$ (i.e., the dotted line obtained from the Nernst equation ${ }^{3)}$ ), thus indicating that pressurization reduces cell loss.

Output voltage is the remainder of subtracting ohmic loss, concentration overvoltage and activation overvoltage from Nernst voltage. Ohmic loss and concentration overvoltage do not depend on operating pressure, so the voltage rise over Nernst voltage is due to the decrease in the activation overvoltage. As the fuel gas composition in the anode changes largely by electrochemical reaction, the effect of the anode on activation overvoltage needs to be studied. We discuss the dependence of activation overvoltage of the anode on operating pressure in the $3^{\text {rd }}$ section.

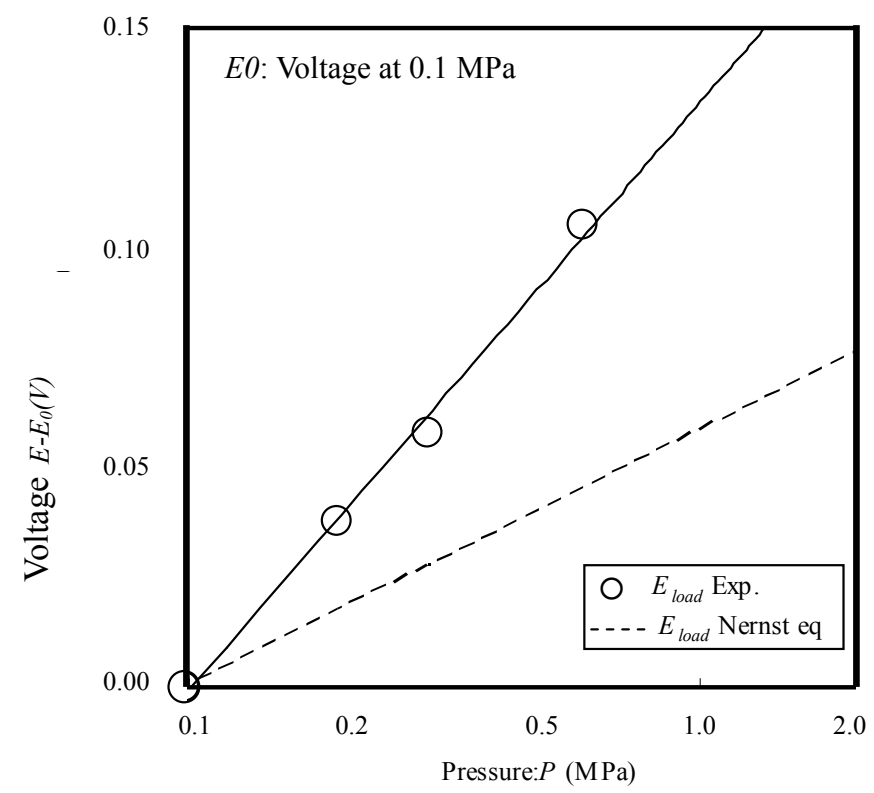

Fig. 6 Effect of voltage on operating pressure 


\section{Anode polarization characteristics}

\subsection{Measurement procedure}

To measure the anode loss behavior accompanying mass transfer, current interruption was measured using the test apparatus in Fig. 2. Cell loss, that is overvoltage: $\eta$, is made up of $\eta_{s}$ and ohmic loss. Ohmic loss rapidly responds to shifts in load, but concentration and activate overvoltage respond slowly. The current interruption ${ }^{4)}$ enables the separation of these factors, and is illustrated in a schematic way in Fig. 7. When the current is quickly interrupted the time-dependent voltage change in electrode is measured, and the polarizations are separated.

A reference electrode was installed in the cell to enable separation of the loss from the anode in the cell. The equivalent circuit and electrode setup is shown in Figure 8. By using the current interruption to measure the difference in potential between R22 and R21, the slow polarization of anode in cell No.21 was separated. Using the separate loading method shown in Fig. 9, loads corresponding to No.1 No.20 were varied and the fuel gas composition at No.21 cell inlet was changed.

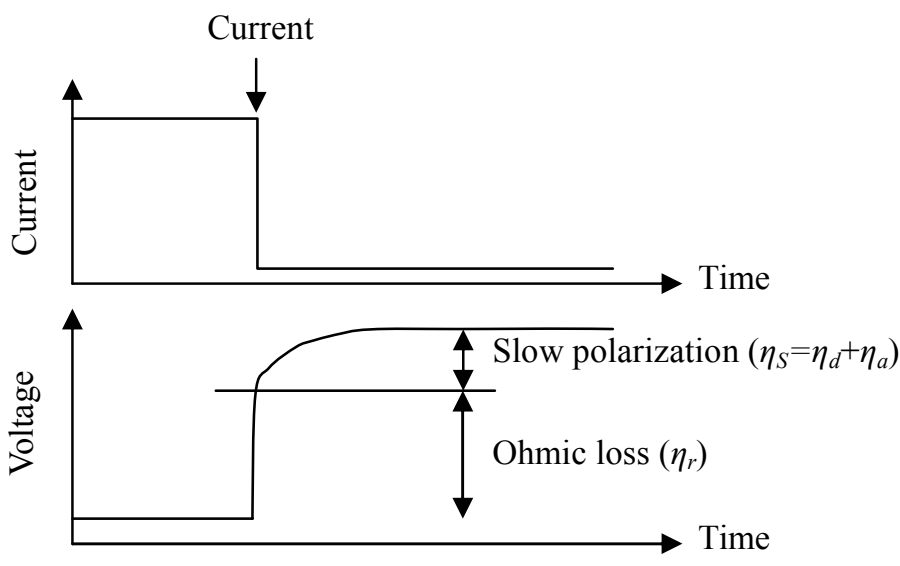

Fig. 7 Current interrupter method

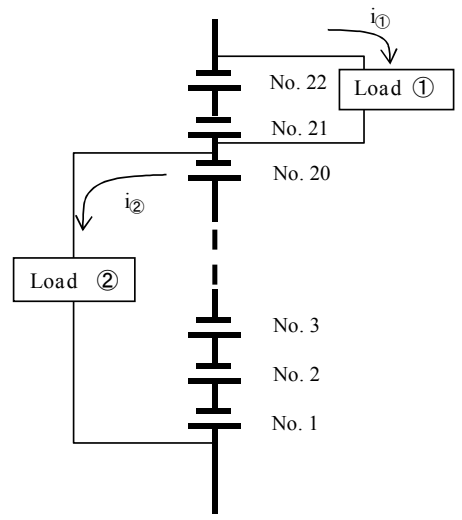

Fig. 9 Control of consumption of fuel gas

\subsection{Test results}

To ascertain the difference affecting the polarization measured in conjunction with the pressurized generation test, the current interruption was used to separate the loss resulting 
from electrical resistance and other slow polarization with respect to the anode. For fuel composition of $\mathrm{H}_{2} / \mathrm{N}_{2} / \mathrm{H}_{2} \mathrm{O}=67 / 30 / 3 \%$, Figs. 10 and 11 respectively indicates the ohmic loss $\eta_{r}$ and slow polarization $\eta_{s}$ at the various operation pressures. The ohmic loss is in proportion to the current, and is constant regardless of the pressure change. However, the slow polarization decreases with rising pressure.

To measure the effect of fuel composition on the polarizations at the anode, the percentages of hydrogen and steam in the fuel were varied, and the polarizations accompanying substance movement were measured. The results for when current is $I 1.86 \mathrm{~A}$ is shown in Figure 12. Slow polarization is affected by the percentages of hydrogen and steam. Measurements were repeated a few times to increase the accuracy.

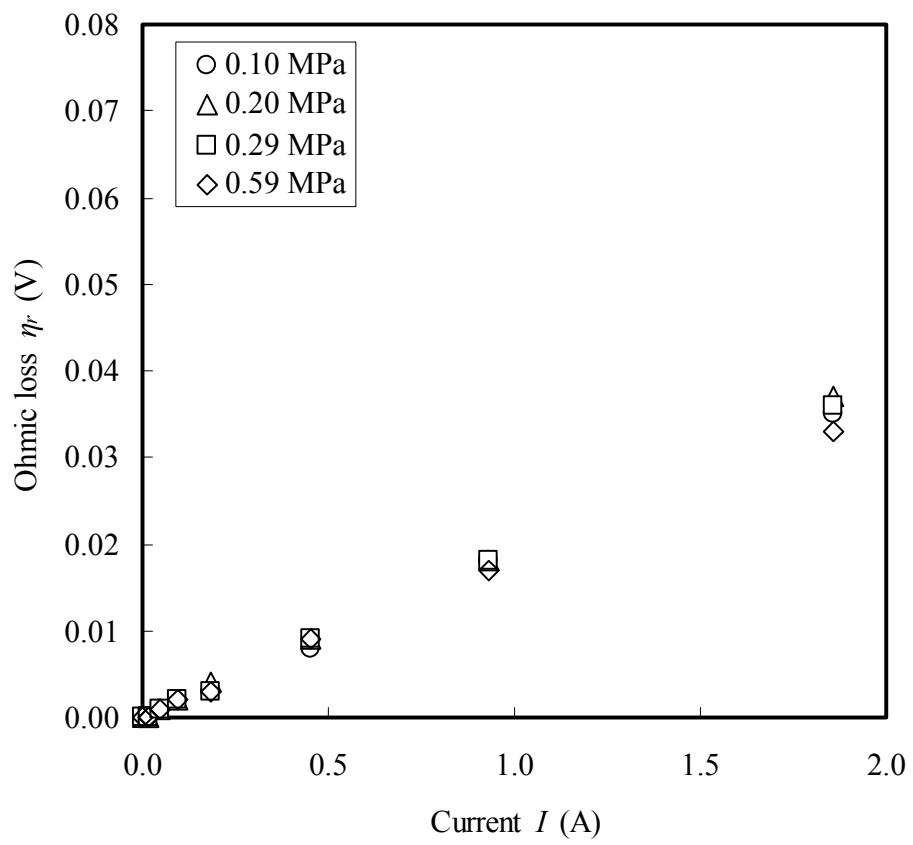

Fig. 10 Ohmic loss

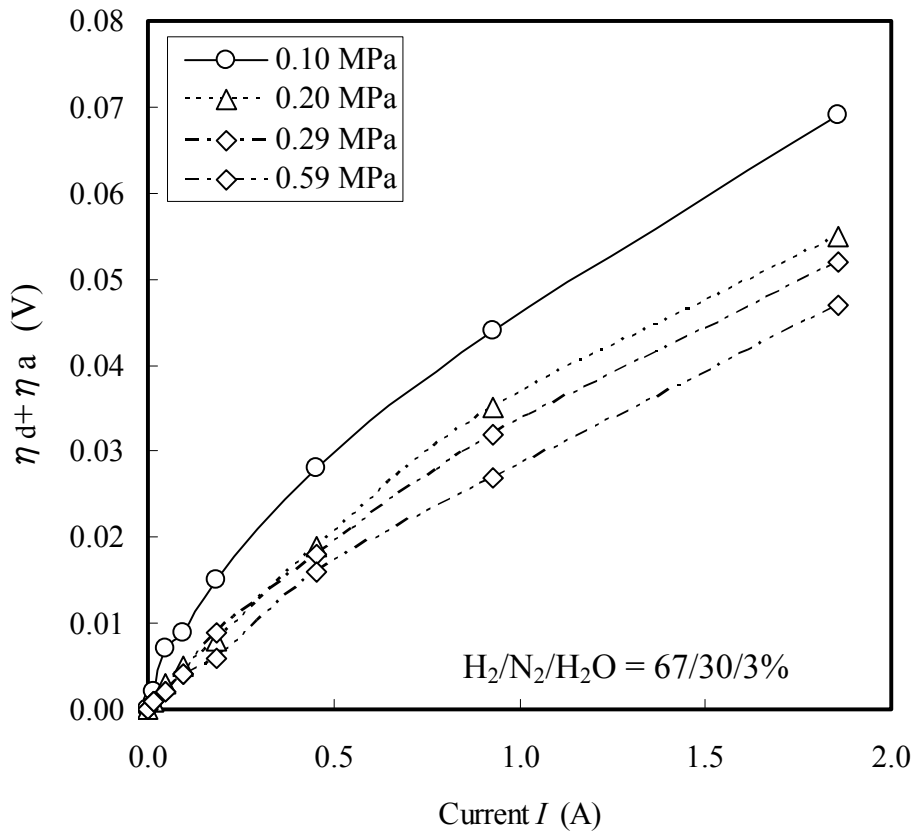

Fig. 11 Slow polarization 


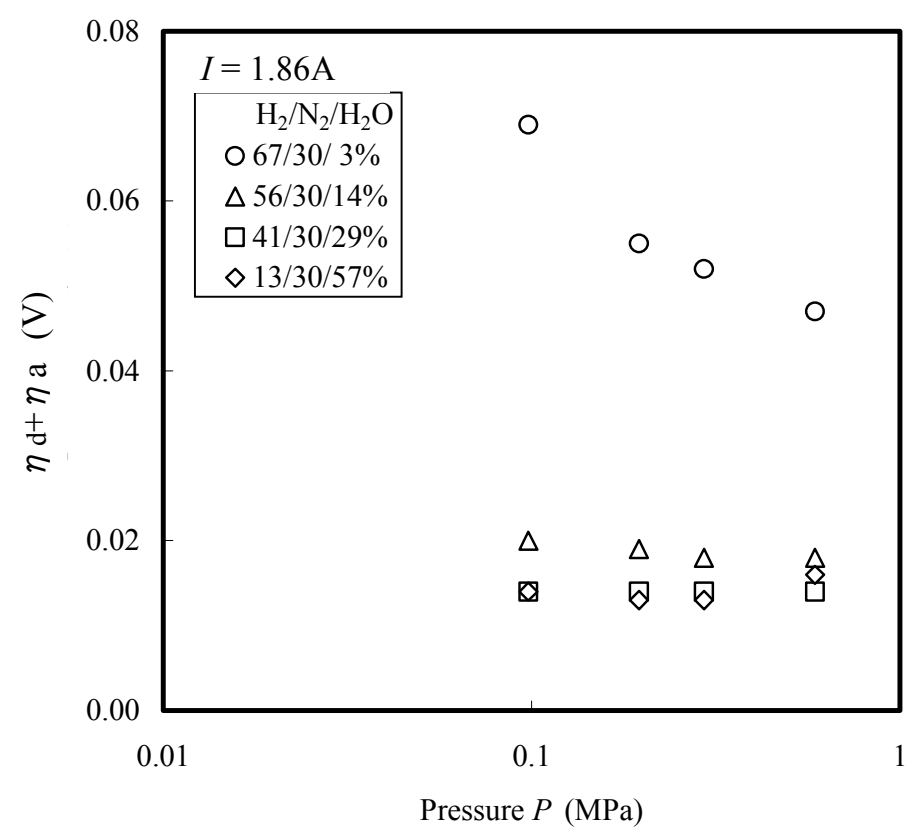

Fig. 12 Effect of fuel gas composition on $\eta \mathrm{d}+\eta \mathrm{a}$

\section{Separation of Activation Overvoltage and Concentration Overvoltage}

\subsection{Test apparatus and measurement method}

Mass transfer polarization loss $\eta_{s}$ is composed of two factors: one is concentration overvoltage $\eta_{d}$ resulting from gas diffusion, and the other is activation overvoltage $\eta_{a}$, which represents the loss accompanying the reaction. Here, the activation overvoltage is separated as follows to obtain a formula for predicting concentration overvoltage.

The thickness of the anode layer and substrate tube is approximately $100 \mu \mathrm{m}$ and $3 \mathrm{~mm}$, respectively, which means that the substrate tube governs the effect of concentration overvoltage on the anode side. The gas diffusion properties of the substrate tube were measured, and concentration overvoltage during operation was predicted.

The test apparatus used for the measurement is shown in Fig. 13. Hydrogen was introduced into the inside of the substrate tube while nitrogen flowed at the outside. Supplies of both gases were kept constant using a mass flow controller, and the flow volumes and gas concentrations were measured at the outlet after flowing through/around the substrate tube. Equivalent pressure was maintained inside and outside the substrate tube, and the equivalent pressure diffusion flow volume through the tube is measured.

Using the effective diffusion coefficient $D_{A B, e}$ for a porous material with respect to gases A and B, Fick's diffusion equation can be expressed as:

$$
J_{A}=-D_{A B, e} \frac{\partial c_{A}}{\partial_{Z}}
$$

Here, $D_{A B, e}$ is represented in Eq. (2) using the porosity of the material $\varepsilon$, tortuosity factor $\tau$, and gas diffusion coefficient $D_{A B}$ for gas $\mathrm{A}$ and gas $\mathrm{B}^{5)}$. The value for $D_{A B}$ at the measured temperature and pressure for hydrogen and nitrogen is obtained from reference values $^{6}$. Assuming equimolar isobaric diffusion, $D_{A B, e}$ becomes constant, and $D_{A B, e}$ can be obtained from Eq. (1) using the measured value of diffusion flow volume $J_{A}$. This value and the value of $D_{A B}$, can be used to obtained $\varepsilon / \tau$ from Eq. (2). The value of $\varepsilon / \tau$ thus obtained for 
the substrate tube was $0.235(-)$. Because $\varepsilon / \tau$ depended on the physical shape of porous channels, we used hydrogen and nitrogen for the measurement. The material properties of these gases are well known. Gas diffusion transfer can be estimated by using the measured value of $\varepsilon / \tau$ for various gases.

$$
D_{A B, e}=D_{A B} \frac{\varepsilon}{\tau}
$$

\subsection{Prediction of concentration overvoltage}

The anode side concentration overvoltage for the SOFC under consideration can be represented as Eq. (3). Here, $p_{A, b}$ is the partial pressure at the reaction interface.

$$
\eta_{d}=-\frac{R T}{2 F} \cdot \ln \left(\frac{p_{H 2}}{p_{H 2, b}}\right)-\frac{R T}{2 F} \cdot \ln \left(\frac{p_{H 2 O, b}}{p_{H 2 O}}\right)
$$

The relationship between mol flux $j\left(\mathrm{~mol} /\left(\mathrm{m}^{2} \cdot \mathrm{s}\right)\right)$ and current density $i$ is expressed as:

$$
j=\frac{i}{2 F}
$$

Assuming that $\varepsilon / \tau$ at room temperature and at the testing temperature are the same, and using the substrate tube thickness and gas diffusion coefficient, Formula (5) can be derived from Eqs. (1), (2), (3) and (4) as follows, and can be used to predict the concentration overvoltage

$$
\eta_{d}=\frac{R T}{2 F} \cdot 1 n\left\{\frac{1-\frac{i}{2 F} \cdot \frac{t}{\varepsilon / \tau \cdot D_{H 2}} \cdot \frac{R T}{p_{H 2}}}{1+\frac{i}{2 F} \cdot \frac{t}{\varepsilon / \tau \cdot D_{H 2 O}} \cdot \frac{R T}{p_{H 2 O}}}\right\}
$$

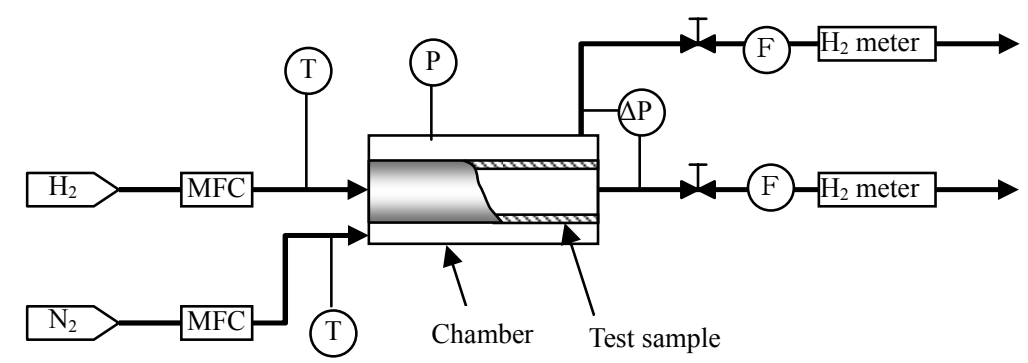

Fig. 13 Schematic view of gas diffusion experimental apparatus

\subsection{Prediction of activation overvoltage}

Using the concentration overvoltage as predicted by Eq. (5) and the given mass transfer loss, the activation overvoltage component was separated. The activation overvoltage predicted by the partial pressures of hydrogen or steam in fuel is shown in Figs. 14 and 15, respectively. As shown in Fig. 14, even when the partial pressure of steam is the same, the activation overvoltage changes with the test pressure. However, as shown in Fig. 15, when the partial pressure of steam is constant, the activation overvoltage is also constant, regardless of the test pressure. This means that activation overvoltage at the anode is more strongly affected by the partial pressure of steam than by the partial pressure of hydrogen. Adsorbed oxygen on the nickel electrode particle might affect the activation overvoltage. 


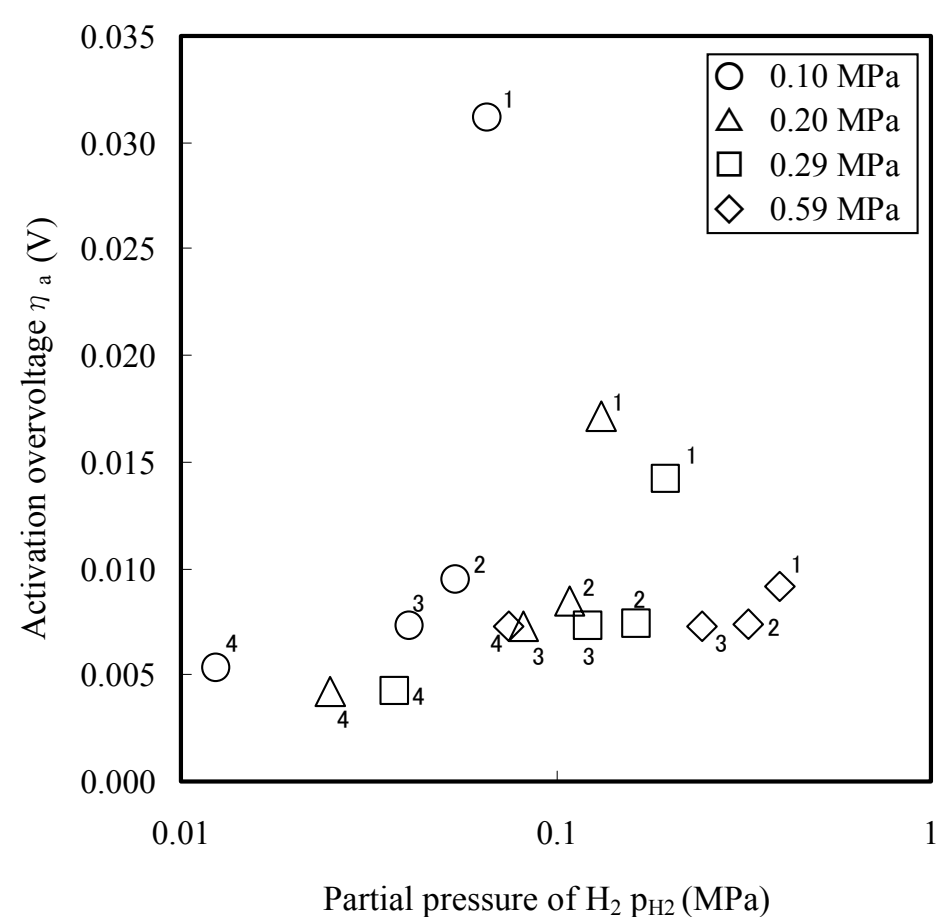

Fig. 14 Effect of $p_{H 2}$ (MPa) on $\eta_{a}$

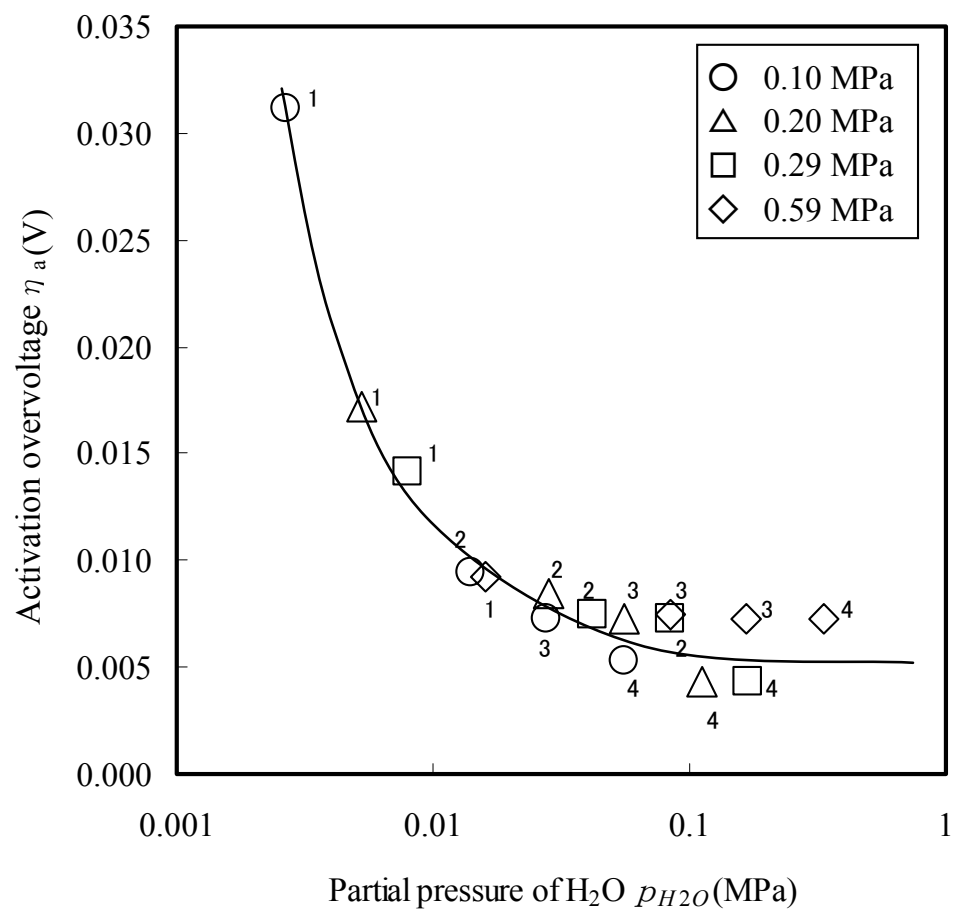

Fig. 15 Effect of $p_{H 2 O}$ on $\eta_{a}$ 


\begin{tabular}{|c|c|c|c|c|}
\hline & \multirow{2}{*}{$\begin{array}{c}\text { Pressure } \\
\mathrm{MPa}\end{array}$} & \multicolumn{3}{|c|}{ Fuel gas composition vol \% } \\
\hline & & $\mathrm{H}_{2}$ & $\mathrm{~N}_{2}$ & $\mathrm{H}_{2} \mathrm{O}$ \\
\hline$\bigcirc_{1}$ & 0.1 & \multirow{4}{*}{67} & \multirow{4}{*}{30} & \multirow{4}{*}{3} \\
\hline$\triangle_{1}$ & 0.2 & & & \\
\hline$\square_{1}$ & 0.29 & & & \\
\hline$\diamond_{1}$ & 0.59 & & & \\
\hline $\mathrm{O}_{2}$ & 0.1 & \multirow{4}{*}{56} & \multirow{4}{*}{30} & \multirow{4}{*}{14} \\
\hline$\triangle_{2}$ & 0.2 & & & \\
\hline$\square_{2}$ & 0.29 & & & \\
\hline$\searrow_{2}$ & 0.59 & & & \\
\hline $\mathrm{O}_{3}$ & 0.1 & \multirow{4}{*}{41} & \multirow{4}{*}{30} & \multirow{4}{*}{29} \\
\hline$\triangle_{3}$ & 0.2 & & & \\
\hline$\square_{3}$ & 0.29 & & & \\
\hline$\diamond_{3}$ & 0.59 & & & \\
\hline $\mathrm{O}_{4}$ & 0.1 & \multirow{4}{*}{13} & \multirow{4}{*}{30} & \multirow{4}{*}{57} \\
\hline$\triangle_{4}$ & 0.2 & & & \\
\hline$\square_{4}$ & 0.29 & & & \\
\hline$\diamond_{4}$ & 0.59 & & & \\
\hline
\end{tabular}

\section{Conclusion}

Pressurized electrical generation testing of a cylindrical SOFC cell stack was conducted. We used $\mathrm{H}_{2} / \mathrm{N}_{2} / \mathrm{H}_{2} \mathrm{O}$ fuel at $900^{\circ} \mathrm{C}$ and with a pressure of 0.1 0.59 MPa. The cell performance under pressurization as well as the effect of fuel composition and pressure on anode loss were clarified. Results were obtained as follows:

1) Cell voltage rises with operating pressure.

2) The increase in voltage due to pressurization from 0.1 to $0.59 \mathrm{MPa}$ was $0.105 \mathrm{~V}$, which is greater than the rise in electromotive force given by the Nernst equation. Pressurization results in reduced loss.

3) Loss at the anode due to electrical resistance is not affected by operating pressure, but the loss accompanying polarization decreases with increased pressure.

4) Among the losses accompanying polarization, the concentration overvoltage changes with the fuel composition, but is not affected by pressure.

5) Among the losses accompanying polarization, the activation overvoltage is determined in accordance with the partial pressure of steam in fuel.

The research reported here focused on anode loss when using $\mathrm{H}_{2} / \mathrm{N}_{2} / \mathrm{H}_{2} \mathrm{O}$ fuel. To establish a performance prediction method for SOFCs, we need to ascertain how the anode performs when practical fuels such as natural gas and gasified coal gas are used, as well as ascertaining cathode loss. 


\section{References}

1) Hashimoto A., Hisatome N., Nagata K., Ikeda K., and Kosaka K., MHI Technology Review, Vol.34, No.1, p38 (1997).

2) Tsukuda H., Notomi A., Hisatome N., Application of plasma spraying to tubular-type Solid Oxide Fuel Cells production, Journal of Thermal Spray Technology, Vol. 9(3), pp364-368 (2000).

3) Tamura H., Matsuda Y., Gendaidenkikagaku [Modern Electrochemistry], Baifukan (1977).

4) Niki et al., Suteppu nyuroku shingo ni tai suru denkyoku-kei no otai [Electrode Response to Step Input Signals], Denki kagaku [Electrochemistry], Vol.40, No.7, pp462-468 (1972).

5) The Society of Chemical Engineers, Japan, Kagaku kogaku binran kaitei goban [Chemical Engineering Handbook, Revised $5^{\text {th }}$ Edition], p. 1111 (1991).

6) Japan Society of Mechanical Engineers, Dennetsu kogaku shiryo kaitei dai-yonban [Thermal Engineering Reference Revised $4^{\text {th }}$ Edition], p356 (1986). 